\title{
Molecular apocrine breast cancers are aggressive estrogen receptor negative tumors overexpressing either HER2 or GCDFP15
}

\author{
Jacqueline Lehmann-Che ${ }^{1,2,3+}$, Anne-Sophie Hamy ${ }^{4{ }^{*}}$, Raphaël Porcher ${ }^{5}$, Marc Barritault ${ }^{1,2}$, Fatiha Bouhidel ${ }^{6}$, \\ Hanadi Habuellelah ${ }^{4}$, Solenne Leman-Detours ${ }^{4}$, Anne de Roquancourt ${ }^{6}$, Laurence Cahen-Doidy ${ }^{8}$, Edwige Bourstyn ${ }^{4}$, \\ Patricia de Cremoux ${ }^{1,2,3}$, Cedric de Bazelaire ${ }^{9}$, Marcela Albiter ${ }^{9}$, Sylvie Giacchetti ${ }^{4}$, Caroline Cuvier ${ }^{4}$, Anne Janin ${ }^{6,7}$, \\ Marc Espié ${ }^{4}$, Hugues de Thé ${ }^{1,2,3}$ and Philippe Bertheau $u^{3,6,7^{*}}$
}

\begin{abstract}
Introduction: Molecular apocrine (MA) tumors are estrogen receptor (ER) negative breast cancers characterized by androgen receptor (AR) expression. We analyzed a group of 58 transcriptionally defined MA tumors and proposed a new tool to identify these tumors.

Methods: We performed quantitative reverse transcription PCR (qRT-PCR) for ESR1, AR, FOXA1 and AR-related genes, and immunohistochemistry (IHC) for ER, PR, Human Epidermal Growth Factor Receptor 2 (HER2), CK5/6, CK17, EGFR, Ki67, AR, FOXA1 and GCDFP15 and we analyzed clinical features.

Results: MA tumors were all characterized by ESR1(-) AR(+) FOXA1(+) and AR-related genes positive mRNA profile. IHC staining on these tumors showed 93\% ER(-), only 58\% AR(+) and 90\% FOXA1(+). 67\% and 57\% MA tumors were HER2(3+) and GCDFP15(+), respectively. Almost all MA tumors (94\%) had the IHC signature HER2(3+) or GCDFP15(+) but none of the 13 control basal-like (BL) tumors did. Clinically, MA tumors were rather aggressive, with poor prognostic factors.
\end{abstract}

Conclusion: MA tumors could be better defined by their qRT-PCR-AR profile than by AR IHC. In addition, we found that HER2 or GCDFP15 protein overexpression is a sensitive and specific tool to differentiate MA from BL in the context of ER negative tumors. A composite molecular and IHC signature could, therefore, help to identify MA tumors in daily practice.

Keywords: cancer, breast carcinoma, molecular apocrine, estrogen receptor, HER2, GCDFP15, triple negative, basallike

\section{Introduction}

Breast cancer is the most common invasive cancer in women. Sex steroid hormones estrogen and progesterone are key drivers in the carcinogenesis through their actions on estrogen receptor alpha (ER) and progesterone receptor (PR). In daily practice, breast cancer molecular

\footnotetext{
* Correspondence: hamyannesophie@gmail.com; philippe.bertheau@sls.aphp. $\mathrm{fr}$

+ Contributed equally

${ }^{3}$ University Paris Diderot, Sorbonne Paris Cité, Paris, 75010, France

${ }^{4}$ AP-HP, Hosp Saint-Louis, Breast Diseases Center, 1 av C. Vellefaux, Paris,

75010, France

Full list of author information is available at the end of the article
}

classification is based on the immunohistochemical expression of these receptors (ER and PR) and of Human Epidermal Growth Factor Receptor 2 (HER2), a member of the epidermal growth factor receptor family. However, the androgen receptor (AR), another member of the steroid receptor family, is also largely expressed in more than $70 \%$ of breast cancers and is now clearly implicated in the pathogenesis of breast cancer [1]. Although largely coexpressed with ER, AR can also be overexpressed in ER (-) breast tumors [2]. The ER(-) tumors represent $30 \%$ of breast cancers and are highly heterogeneous, including at least basal-like (BL) tumors and part of the HER2 positive tumors. Yet, among these ER(-) tumors, several teams

\section{() Biomed Central}


have identified the molecular apocrine breast cancer (MA) subtype, characterized by AR expression and AR pathway activation on genome-wide expression analyses, paradoxical expression of genes known to be ER targets or expressed in ER(+) tumors and HER2 overexpression in around 50\% of cases [3] [4]. The existence of this MA subgroup suggests a new molecular classification for breast cancers, including luminal, MA and BL breast cancer subgroups [5]. AR overexpression may provide a new therapeutic target for breast cancer [6], especially in patients with ER(-) tumors that do not benefit from endocrine or HER2 targeted therapies. A potential therapeutic effect of AR inhibition in MA subtype has already been shown using in vitro models [4]. However, there is no clear consensus yet to define the MA subgroup, except by transcriptomic analysis. An easy and reproducible method to identify MA breast cancers is needed to better understand the behavior of these tumors and to enable their inclusion in specific trials.

Here, we used a molecular apocrine qRT-PCR signature initially defined on a set of breast cancer samples annotated with their transcriptional profiles. We retrospectively identified a group of MA tumors based on this signature. We described their clinical, molecular and pathological features and we identified a new simplified immunohistochemical and molecular signature leading to an easy to use and reproducible diagnostic tool for these tumors.

\section{Materials and methods Patients}

In order to identify patients with molecular apocrine tumors, we proposed a qRT-PCR molecular apocrine (MA) signature defined by the absence of ESR1 overexpression (ER-), AR and FOXA1 overexpression, as well as overexpression of three of five genes related to the AR pathway (Agr2, ALCAM, SPDEF, TTF3, UGT2B28A), according to what was previously described in the literature $[4,5]$.

To validate this MA signature in the context of ERnegative tumors, we constituted a validation set of 45 ER-negative samples with available microarray data (E-MTAB-365, GSE26639) predicted to be molecular apocrine (32 cases) or basal-like (13 cases) by our previously published predictor [7]. These validation data are available in Additional file 1. The qRT-PCR signature discriminated correctly the 32 tumors predicted to be molecular apocrine by the microarray predictor.

With this validated qRT-PCR signature, we retrospectively screened 502 breast cancer patients treated in St. Louis Hospital (Paris) between 1996 and 2008 and have frozen samples available for molecular analysis. We identified 58 molecular apocrine tumors and used 13 basal-like tumors as a control group. Clinical data including age, type of surgery, type of treatment, occurrence and type of relapse and current status were obtained from the Breast Disease Center of the hospital by review of medical charts. Pathological data including histological type, grade, tumor size, peritumoral vascular invasion and stage were recorded. Samples were provided by the biological resource center after approval of the Saint Louis hospital ethical review board (Paris, France: agreement $n^{\circ}$ DC 2009-929), following the Ethics and Legal national French rules for the patients' information and consent (ANAES, HAS and INCa). All patients were informed of the study and did not oppose it, according to our Institutional Review Board recommendations.

\section{Molecular analyses}

Total RNA was extracted from fresh tumor tissue sections using phenol/chloroform extraction. After a reverse transcription step (Superscript II reverse transcriptase, Life Technologies SAS, Saint Aubin, France), we analyzed ESR1, AR, FOXA1 and AR-related genes (UGT2B28A, $A L C A M, A G R 2$, SPDEF and TTF3) expression using specific primers and probes or Gene Expression Assays (Applied Biosystems Inc., Foster City, CA, USA) (ER [8], AR (Hs00171172_m1), FOXA1 (Hs00270129_m1), UGT2B28A (Hs00852540_s1), ALCAM (Hs00233455_m1), AGR2 (Hs00180702_m1), SPDEF (Hs01026048_m1), TFF3 (Hs00173625_m1) by quantitative real time PCR (qPCR, Taqman 7500, Applied Biosystems Inc.). We performed relative quantification using the TATA box binding protein $(T B P)$ gene as the endogenous control and final results were expressed as normalized ratios (target gene/ reference gene). AR and FOXA1 were considered as overexpressed with a relative ratio cut-off at 100. The cut-off ratios were determined on the histogram of mRNA ratio distribution on our tumors. We showed a clear bimodal distribution in all our samples, using the mixture model of two Gaussian distributions with optimal cut-off at the intersection of the probability density functions [9]. We determined ERBB2 (HER2) expression level by qRT-PCR as previously described [10]. We also analyzed TP53 status by functional assay in yeast (FASAY) as originally described in [11,12] and as described in [13].

After DNA extraction using phenol/chloroform method, we analysed PIK3CA mutational status (hot spots: E542K, E545K and H1047R) by allelic discrimination on a LC480 cycler (Roche Diagnostics, Meylan, France) [14].

\section{Immunohistochemistry}

We performed the following immunohistochemical stainings: ER (clone 6F11, dilution 1/50, Novocastra Laboratories, Neucastle Upon Tyne, UK), PR (clone 312, dilution $1 / 75$, Novocastra), HER2 (clone CB11, dilution 1/250, Novocastra), Ki-67 (clone Mib 1, dilution 1/100, DakoFrance Les Ulis, France), CK5/6 (clone D5/16 B4, dilution 1/50, Dako), CK17 (clone E3, dilution 1/75, Dako), EGFR 
(clone Dak-H1-WT, dilution 1/20, Dako), AR (clone AR441, dilution 1/20, Dako), FOXA1 (clone 2F83, dilution 1/500, Abcam, paris, France) and GCDFP15 (clone 23A3, dilution 1/50, Dako). Evaluation of HER2 immunostaining was scored according to ASCO guidelines [15,16]. Dual silver in situ hybridization (Roche Ventana, Tucson Arizona, USA) was used in 4 HER2(2+) cases and the polyclonal anti-HER2 antibody (Dako) was used in another HER2 $(2+)$ case. Cytoplasmic immunostainings for GCDFP15 and for basal cytokeratins were considered positive if at least $5 \%$ of the tumor cells were positive. All other immunostainings were nuclear stainings (ER, PR, FOXA1, AR) and were considered positive if at least $10 \%$ of the tumor cells were positive. For Ki67 immunostaining, the percentage of positive nuclei was noted.

\section{Statistical analyses}

Immunohistochemical protein and mRNA expression were compared between the two tumor groups using Fisher's exact tests. Performance of immunohistochemical signatures to discriminate between apocrine and basal-like tumors was expressed in terms of sensitivity, specificity and the area under the receiver operating characteristics curve (AUC). The survival data, overall survival (OS) and disease free survival (DFS), were estimated using Kaplan-Meier product-limit estimator.

A tumor signature was developed by using classification trees (CART algorithm) [17]. Briefly, this method builds up a tree model to reduce misclassification rates or tree deviance, with a penalization for the tree complexity. The CART model was first built up to a maximum tree, then upward tree pruning through 10-fold cross-validation was used to cut the tree down [18]. Multiple correspondence analysis (MCA) was used to graphically display the association between the expressions of the different proteins. All tests were two-sided and $P$-values $<0.05$ were considered as indicating significant association. Analyses were performed using the $\mathrm{R}$ statistical software version 2.10 .1 (The R Foundation for Statistical Computing, Vienna, Austria) [19], with the package tree for CART analyses [20].

\section{Results}

Clinical description of the group of patients

We constituted a cohort of 58 breast cancers presenting the qRT-PCR signature of the molecular apocrine subgroup and we used the 13 basal-like tumors as a control group. The molecular apocrine group presented a mean age at diagnosis of 54 years and a majority of patients had a clinical tumor size larger than $2 \mathrm{~cm}$ (T2-T3-T4, 81\%). All but seven patients received chemotherapy (neoadjuvant $15 \%$, adjuvant $59 \%$, neoadjuvant and adjuvant $14 \%$ ) and $28 \%$ received trastuzumab (Table 1 ). Clinical data for basal-like control tumors are also available in Table 1 .
Table 1 Patient and tumor characteristics

\begin{tabular}{|c|c|c|}
\hline Characteristics & $\begin{array}{c}\text { Molecular } \\
\text { apocrine } \\
\text { No. patients (\%) }\end{array}$ & $\begin{array}{l}\text { Basal-like } \\
\text { No. patients } \\
(\%)\end{array}$ \\
\hline All patients & 58 & 13 \\
\hline Age at diagnosis (range) & $\begin{array}{c}54 \text { y.o. } \\
\text { (32 to } 86)\end{array}$ & $\begin{array}{c}43 \text { y.o. } \\
\text { (27 to } 63 \text { ) }\end{array}$ \\
\hline $\begin{array}{l}\text { Menopausal status } \\
\text { - premenopausal } \\
\text { - postmenopausal }\end{array}$ & $\begin{array}{l}26(45) \\
32(55)\end{array}$ & $\begin{array}{c}10(77) \\
3(23)\end{array}$ \\
\hline $\begin{array}{l}\text { Clinical tumor size } \\
\text {-T0-T1 } \\
\text {-T2-T3-T4 }\end{array}$ & $\begin{array}{l}11(19) \\
47(81)\end{array}$ & $\begin{array}{c}0(0) \\
13(100)\end{array}$ \\
\hline $\begin{array}{l}\text { Histology } \\
\text { - Invasive ductal } \\
\text { with Paget disease } \\
\text { with apocrine differentiation } \\
\text { with squamous metaplastic } \\
\text { areas }\end{array}$ & $\begin{array}{c}58(100) \\
4(7) \\
4(7) \\
1(2)\end{array}$ & $\begin{array}{c}13(100) \\
1(8)\end{array}$ \\
\hline In situ component & $44(76)$ & $3(23)$ \\
\hline $\begin{array}{l}\text { Pathological nodal involvment } \\
\text {-N0 } \\
\text {-N1, N2, N3 } \\
\text { no axillary dissection }\end{array}$ & $\begin{aligned} & 22(38) \\
& 33(57) \\
& 3(5)\end{aligned}$ & $\begin{array}{l}11(85) \\
2(15)\end{array}$ \\
\hline $\begin{array}{l}\text { Grading SBR } \\
\quad-G 2 \\
-G 3\end{array}$ & $\begin{array}{l}15(26) \\
43(74)\end{array}$ & $\begin{array}{c}1(8) \\
12(92)\end{array}$ \\
\hline Lymphovascular invasion & $28(48)$ & $1(8)$ \\
\hline $\begin{array}{l}\text { Treatments: } \\
\text { Surgery } \\
\quad \text { - lumpectomy } \\
\quad \text { - mastectomy } \\
\text { - no } \\
\text { Chemotherapy (CT) } \\
\quad \text { - neoadjuvant CT } \\
\text { - adjuvant CT } \\
\text { - neoadjuvant and adjuvant } \\
\text { CT } \\
\text { - no } \\
\text { Radiotherapy } \\
\text { Trastuzumab }\end{array}$ & $\begin{array}{c}18(31) \\
39(67) \\
1(2) \\
9(15) \\
34(59) \\
8(14) \\
7(12) \\
41(71) \\
16(28)\end{array}$ & $\begin{array}{c}0(0) \\
13(100) \\
0(0) \\
0(0) \\
1(8) \\
12(92) \\
0(0) \\
10(77) \\
0(0)\end{array}$ \\
\hline
\end{tabular}

\section{Molecular description of the two groups}

We analyzed the two groups for ESR1, ERBB2, $A R$, $F O X A 1$ and five $A R$-related genes expression by qRTPCR. Molecular apocrine tumors showed lack of ESR1 expression (ER-), overexpression of $A R, F O X A 1$ (Table 2) and of three out of five $A R$-related genes (data not shown). $E R B B 2$ expression level was positive in $68 \%$ of cases. Conversely, all BL tumors showed lack of ESR1, $F O X A 1$ and ERBB2 expression and also lack of $A R$ in $11 / 13$ cases $(85 \%)$ (Table 2 ).

We assessed mutations in the three hotspots of the PIK3CA gene (E542K, E545K and H1047R) in both tumor groups. In the MA group, 11/58 (19\%) mutations on PIK3CA could be detected compared to no mutation case in the BL group (Table 2) with a majority of H1047R mutations, located in the catalytic domain of PIK3CA (exon 20). However, the difference between the two groups was not statistically significant. 
Table 2 Molecular characteristics of the MA and BL tumors groups (\%)

\begin{tabular}{|c|c|c|c|}
\hline & Molecular apocrine & Basal-like & $P$-value \\
\hline No. patients & 58 & 13 & \\
\hline $\begin{array}{l}\text { ER expression (mRNA) (pos >20) } \\
\text {-negative }\end{array}$ & $58(100)$ & $13(100)$ & $>0.99$ \\
\hline $\begin{array}{l}\text { HER2 expression (mRNA) (pos >7) } \\
\text {-positive } \\
\text {-negative } \\
\text {-nd }\end{array}$ & $\begin{array}{l}38(68) \\
18(32) \\
2\end{array}$ & $\begin{array}{l}0(0) \\
13(100) \\
0\end{array}$ & $<0.0001$ \\
\hline $\begin{array}{l}\text { AR expression (mRNA) (pos >100) } \\
\text {-positive } \\
\text {-negative }\end{array}$ & $\begin{array}{l}58(100) \\
0(0)\end{array}$ & $\begin{array}{l}2(15) \\
11(85)\end{array}$ & $<0.0001$ \\
\hline $\begin{array}{l}\text { FOXA1 expression (mRNA) (pos }>100) \\
\text {-positive } \\
\text {-negative }\end{array}$ & $\begin{array}{l}58(100) \\
0(0)\end{array}$ & $\begin{array}{l}0(0) \\
13(100)\end{array}$ & $<0.0001$ \\
\hline $\begin{array}{l}\text { PIK3CA status: } \\
\text {-wild type } \\
\text {-mutated } \\
\text { - exon 9: E542K and E545K } \\
\text { - exon 20: H1047R }\end{array}$ & $\begin{array}{l}47(81) \\
11(19) \\
1 \\
10\end{array}$ & $\begin{array}{l}13(100) \\
0 \\
0 \\
0\end{array}$ & 0.20 \\
\hline $\begin{array}{l}\text { TP53 status (FASAY test) } \\
\text {-functional } \\
\text {-nonfunctional }\end{array}$ & $\begin{array}{l}29(50) \\
29(50)\end{array}$ & $\begin{array}{l}0(0) \\
13(100)\end{array}$ & 0.0005 \\
\hline
\end{tabular}

AR, androgen receptor; BL, basal-like; ER, estrogen receptor; HER2, Human Epidermal Growth Factor Receptor 2; MA, molecular apocrine.

Additionally, we analyzed the TP53 functional status by the FASAY assay and 29/58 (50\%) of MA tumors were p53 nonfunctional compared to $100 \%$ of the BL tumors (Table 2).

\section{Pathological and immunohistochemical description of the two groups}

As shown in Table 1, all MA tumors were ductal invasive carcinoma, with morphological apocrine differentiation in four tumors (7\%), Paget's disease in four others (7\%) and in situ component in 44 patients (76\%). Tumors were grade 3 in 43 patients (74\%), grade 2 in 15 patients (26\%), and lymphovascular invasions were observed in 28 cases (48\%). Pathological data for the BL tumors are also available in Table 1.

IHC profiles among the MA tumors are shown in Table 3 and two examples are given in Figure 1. Almost all tumors were ER(-), PR(-) and 67\% were HER2 (+). Among five HER2(2+) cases, four were ERBB2 amplified as shown by Silver In Situ Hybridization and one case was found negative with a second anti-HER2 antibody (polyclonal, Dako). FOXA1 and AR immunostainings were positive in $90 \%$ and $58 \%$ of MA tumors, respectively, and $57 \%$ were positive for GCDFP15 with 5\% to $90 \%$ stained tumor cells (median 50\%). Conversely, the majority of cases were EGFR(-), CK5/6(-), and CK17(-) and 10/55 (18\%) tumors were below 20\% Ki67 staining (median 30\% stained cells).

Among the four tumors with morphological apocrine differentiation, all were ER(-) and GCDFP15(+), two were $\operatorname{HER} 2(3+)$, two were $\operatorname{AR}(+)$ and three were $\operatorname{EGFR}(+)$.

In comparison, all the $13 \mathrm{BL}$ tumors were $\mathrm{ER}(-) \mathrm{PR}(-)$ HER2(-), AR(-) and GCDFP15(-). Thirty-one percent of
BL tumors were FOXA1(+), 69\% EGFR(+) and 62\% were CK5/6(+) and CK17(+). Two BL tumors (15.4\%) were below the 20\% threshold for Ki67 staining (median 50\% stained cells). There was no difference between the two groups for Ki67 expression (Table 3).

\section{Correlation of molecular and immunohistochemical markers of the two groups}

We compared the two groups of tumors for $A R$ and FOXA1 expressions at protein and mRNA levels. As mentioned, all the MA tumors overexpressed $A R$ and FOXA1 mRNA but only $58 \%$ and $90 \%$ were positive for AR and FOXA1 with IHC, respectively.

The relative mRNA $A R$ ratio was strongly positive in all MA cases (Figure 2), with a higher ratio in $\mathrm{AR} \mathrm{IHC}(+)$ group compared to AR IHC(-) tumors (mean ratio of 2,207 and 1,062, respectively). In the BL subgroup of tumors, we observed a good correlation between AR protein and mRNA levels, all cases showing weak or negative expression (mean value 45.4). These data suggest that $A R$ mRNA determination is more sensitive than AR IHC in MA tumors.

The relative FOXA1 ratio was also positive in all MA cases whatever the IHC staining (Figure 2), but the mean FOXA1 ratio was not significantly different in the $\mathrm{IHC}(+)$ and IHC (-) group (mean ratio 660.3 versus 524.3) In the BL subgroup, lack of FOXA1 expression was concordant at the mRNA and protein levels but four FOXA1 $\mathrm{IHC}(+)$ tumors could not be detected at the mRNA level.

These results suggest that $A R$ and FOXA1 mRNA signatures could not be transposed directly into protein levels and that AR IHC and FOXA1 IHC do not correctly identify the MA subgroup. 


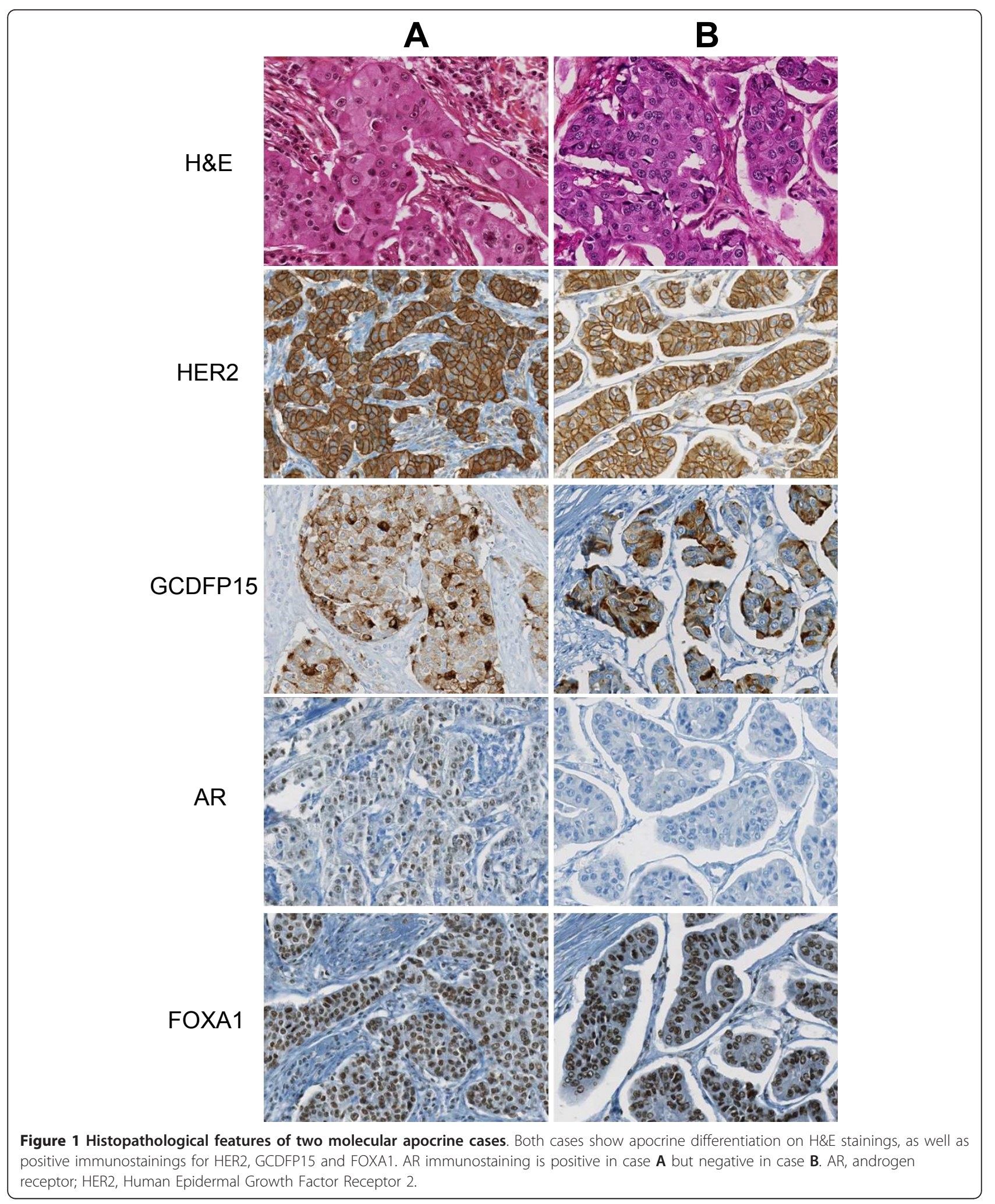


Table 3 Immunohistochemical description of the MA and BL tumors groups (\%).

\begin{tabular}{llll}
\hline & Molecular apocrine & Basal-like & $P$-value \\
\hline No. patients & 58 & 13 & $>0.99$ \\
ER(-) & $54(93)$ & $13(100)$ & $>0.99$ \\
PR(-) & $56(97)$ & $13(100)$ & $<0.0001$ \\
HER2(3+) & $39(67)$ & $0(0)$ & $<0.0001$ \\
GCDFP15(+) & $33(57)$ & $0(0)$ & $<0.0001$ \\
AR(+) & $33(58)$ & $0(0)$ & $<0.0001$ \\
FOXA1(+) & $52(90)$ & $4(31)$ & 0.012 \\
EGFR(-) & $40(70)$ & $4(31)$ & 0.0003 \\
CK5/6(-) & $51(89)$ & $5(38)$ & $<0.0001$ \\
CK17(-) & $54(95)$ & $5(38)$ & 0.27 \\
Ki67 median (range of \% stained cells) & $30(0$ to 80$)$ & $50(0$ to 90$)$ & \\
\hline
\end{tabular}

AR, androgen receptor; BL, basal-like; ER, estrogen receptor; HER2, Human Epidermal Growth Factor Receptor 2; MA, molecular apocrine; PR, progesterone receptor.

Definition of an immunohistochemical and molecular signature of the MA subgroup of tumors

As shown in Table 4, AR IHC positivity, evaluated alone in a ER(-) setting, had a good specificity (100\% (95\% CI: 75 to 99$)$ ) for MA tumors but a poor sensitivity (58\% (95\% CI: 44 to 72 )). Combining AR IHC with FOXA1 IHC did not improve the specificity and the sensitivity. Indeed, the IHC signature $\operatorname{ER}(-) \mathrm{AR}(+)$ FOXA1(+), although being the IHC counterpart of the molecular definition, was found in only $57 \%$ of MA tumors.

We then studied how the $58 \mathrm{MA}$ and $13 \mathrm{BL}$ tumors were distributed according to the following IHC markers: ER, HER2, GCDFP15 and AR (Figure 3). It appeared on this figure that "HER2(3+) OR GCDFP15(+)" cases accounted for 51 out of $54 \mathrm{ER}(-)$ tumors (94\%) but was never observed in BL tumors. This IHC signature "HER2(3+) OR GCDFP15(+)" had a sensitivity and a specificity for apocrine tumors of $94 \%$ and $100 \%$, respectively (Table 4) and is also shown in a tree diagram displaying the best possible marker combination to discriminate MA and BL tumors in the ER negative context (Figure 4). Combining AR gene expression pathway and this IHC signature seems finally to be an efficient composite approach to define MA tumors.

\section{Survival analysis of the two groups}

In the MA subgroup, after a median follow-up of 94 months (range: 0.8 to 175 months), 33 events (local recurrence $n=8$, contralateral $n=3$, distant metastasis
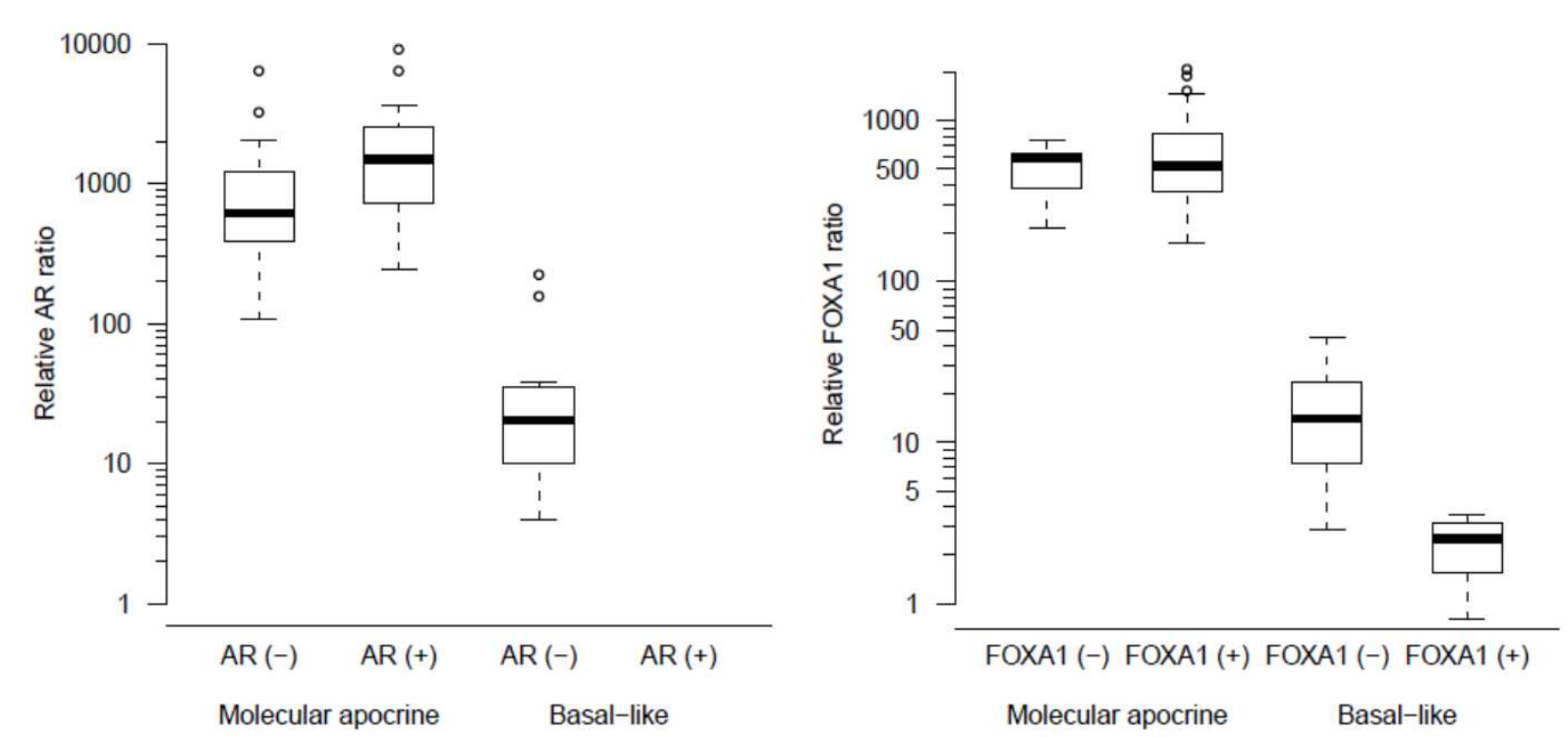

Figure 2 Relationship between AR and FOXA1 qRT-PCR and IHC in the MA and BL tumors groups. Positive cut-off ratio is 100. Boxplots indicate first quartile, median and third quartile. Outliers are indicated by small circles. AR, androgen receptor; $\mathrm{BL}$, basal-like; IHC, immunohistochemistry; MA, molecular apocrine. 
Table 4 Sensitivity and specificity of the IHC signatures of MA tumors in ER(-) subgroup.

\begin{tabular}{llll}
\hline IHC biomarker & Sensitivity $\mathbf{9 5 \%}$ Cl) & Specificity $\mathbf{9 5 \%}$ CI) & AUC \\
\hline AR(+) & $58 \%(44$ to 72$)$ & $100 \%(75$ to 99$)$ & $0.792(0.726$ to 0.859$)$ \\
AR(+) and FOXA1(+) & $57 \%(43$ to 71$)$ & $100 \%(75$ to 99$)$ & $0.787(0.721$ to 0.853$)$ \\
HER2(3+) or GCDFP15(+) & $94 \%(85$ to 99$)$ & $100 \%(75$ to 99) & $0.972(0.942$ to 0.999$)$ \\
\hline
\end{tabular}

AR, androgen receptor; ER, estrogen receptor; HER2, Human Epidermal Growth Factor Receptor 2; IHC, immunohistochemistry; MA, molecular apocrine.

$n=22$ ), and 21 deaths occurred. Five-year disease free survival (DFS) and overall survival (OS) were 66\% and $77 \%$, respectively. In the BL subgroup, the median follow-up was 122 months (range: 28; 195) and five-year DFS and OS were $79 \%$ and $73 \%$, respectively (Figure 5 ). No statistical difference was observed between the two groups ( $p=0.35$ for DFS and $p=0.22$ for OS). Also, in the MA subgroup, there was no statistically significant difference in terms of DFS according to the IHC status $\operatorname{AR}(+) / \operatorname{AR}(-), \operatorname{HER} 2(3+) / \operatorname{HER} 2(-)$ or GCDFP15(+)/GCDFP15(-) of the tumors (see Additional file 2).

\section{Discussion}

Breast cancers are highly hormone-dependent tumors. The prominent role of the estrogen and progesterone receptors as prognostic factors and treatment targets is well established. Despite the fact that androgen expression in breast cancer has been known for a long time, interest for this type of hormone nuclear receptor as a possible biomarker is more recent. The description of the MA breast cancer subgroup raises new questions about AR implication in prognosis or prediction of response to hormone blockade in an ER-negative setting. Moreover, easy and robust identification of this new tumor subgroup is needed for proper evaluation. We report here a series of 58 MA breast tumors and compare protein and mRNA expression of genes included in the transcriptomic MA signature [4]. We propose a sensitive and specific composite immunohistochemical and molecular diagnostic signature.

MA tumors were originally described by Farmer et al. [3] who identified, with microarray data, a new subgroup of breast tumors which often displayed apocrine morphology (five out of six cases), and they, therefore, suggested that these tumors be called "MA breast carcinomas". To date, data have been somewhat confusing regarding the relationship between MA breast tumors and pathologically-defined apocrine tumors. On breast tissue sections, histological apocrine changes are defined by eosinophilic cytoplasms with fine granularity, large nuclei with occasional large nucleoli and frequent apical snouts [21,22]. The term "apocrine carcinoma", as defined by microscopical examination, should be used for neoplasms composed of at least $90 \%$ apocrine type epithelium [23]. These tumors account for $0.5 \%$ to $4 \%$ of breast carcinomas and mostly occur at advanced ages. Their prognosis is similar to that of other breast carcinomas [24]. In our study, we

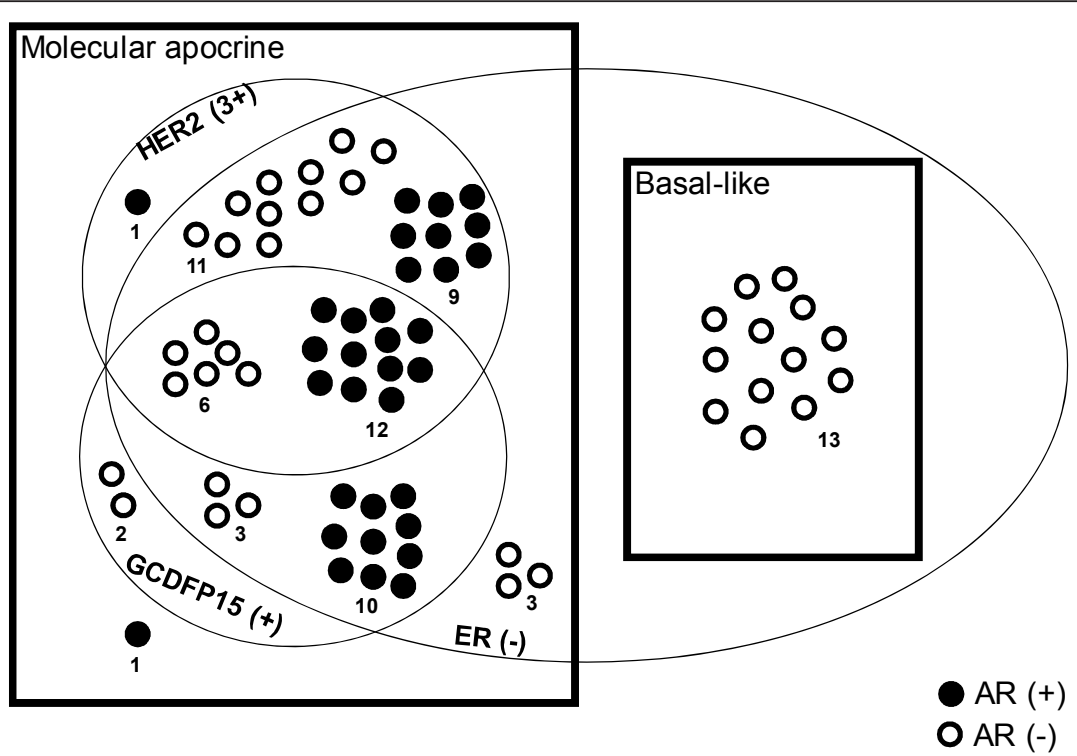

Figure 3 Distribution of the MA and BL tumors according to ER, HER2, GCDFP15 and AR immunostainings. Numbers of tumors in each subgroup are indicated. AR, androgen receptor; BL, basal-like; ER, estrogen receptor; HER2, Human Epidermal Growth Factor Receptor 2; MA, molecular apocrine. 


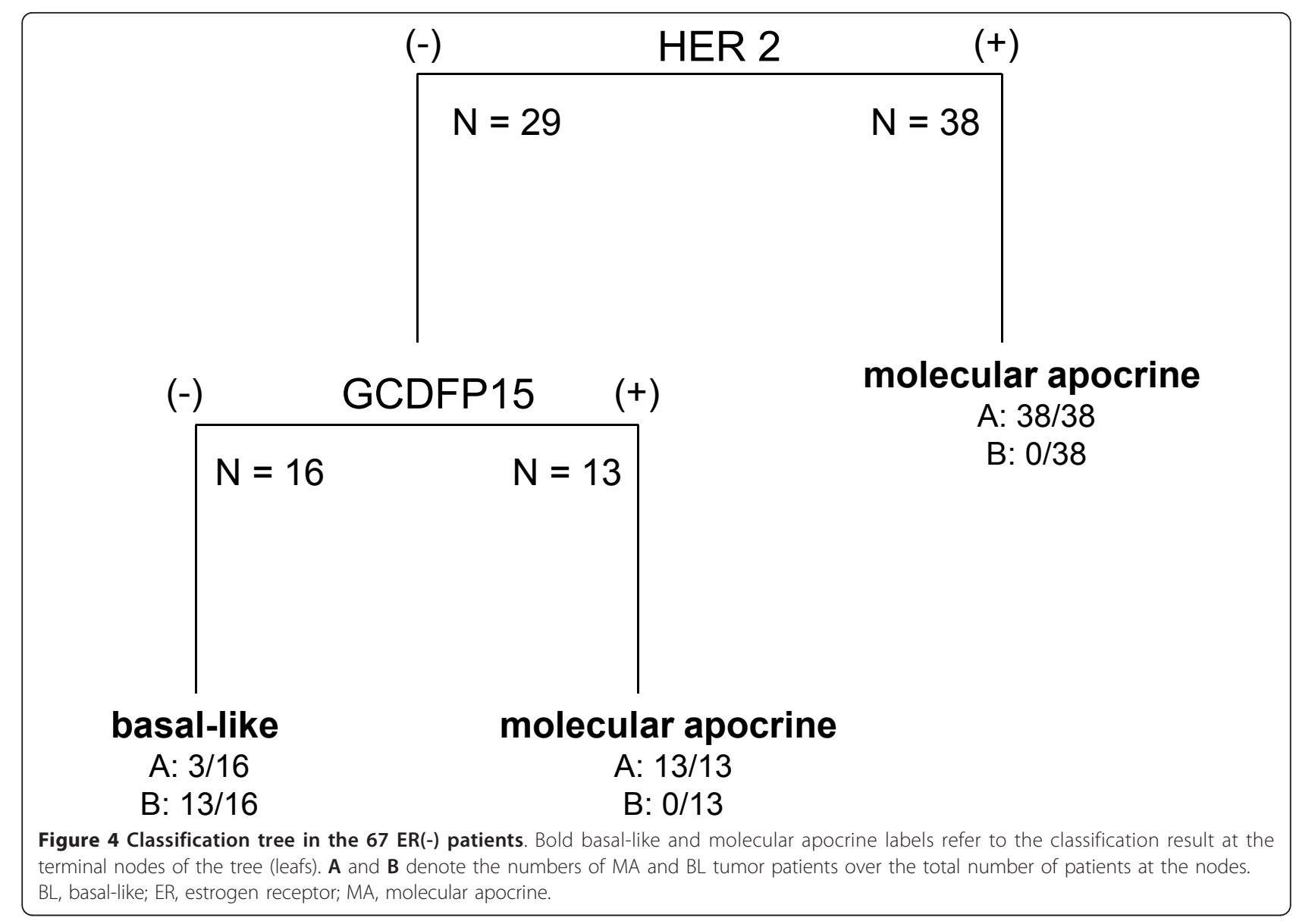

found only four morphological apocrine tumors among 58 MA cases, strongly suggesting that the MA subtype could in fact be much broader than initially reported by Farmer et al. [3].
A frequently reported feature of apocrine differentiation, whatever being defined morphologically or molecularly, is a strong androgen receptor expression in an otherwise ER(-) background. Indeed, although sometimes
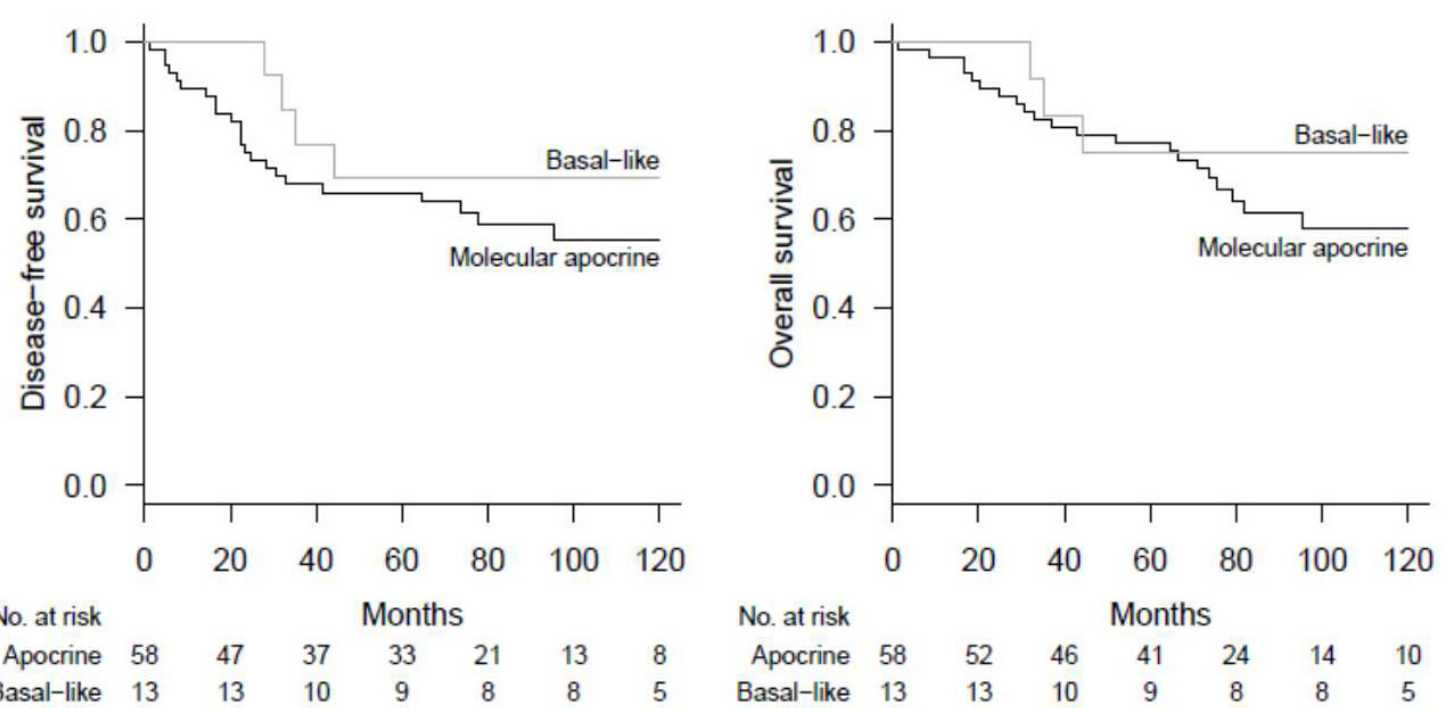

Figure 5 DFS and OS curves of the 58 MA and 13 BL tumors. DFS, disease free survival; OS, overall survival. 
reported to belong to several molecular subtypes of breast cancer [25], morphological apocrine carcinomas are almost always ER(-) tumors [26] and, among 19 cases, all were ER(-), PR(-) and strongly AR(+) by IHC [27]. Currently, the MA subgroup is characterized by $A R$ gene overexpression and Niemeier et al. [28] suggested that the $\operatorname{ER}(-) / P R(-) / \operatorname{HER} 2(+) / \mathrm{AR}(+)$ or $\mathrm{ER}(-) / \mathrm{PR}$ $(-) /$ HER2(-)/AR(+) IHC signature could include the "MA group" described previously by Farmer et al. [3]. However, our results raise the question whether AR, as assessed by IHC, is a good marker to define this tumor subgroup. Indeed, although this marker was pretty specific for MA carcinomas, since it was absent in BL cancers, we found that only $58 \%$ of MA tumors were $\operatorname{IHC} \mathrm{AR}(+)$, thus making this marker not sensitive enough for clinical use. Conversely, $A R$ mRNA, evaluated by qRT-PCR, was highly expressed, whatever the level of IHC expression. Doane et al. [4] also found that only $50 \%$ of MA tumors expressed AR by IHC, despite high $A R$ expression levels in microarrays data. This dissociation between AR mRNA and protein expression may be due to a lower sensitivity of immunohistochemistry or a faster AR degradation due to activation, leading to undetectable protein.

AR related genes AGR2, ALCAM SPDEF and TTF3 were found in the top 50 significantly overexpressed genes in the transcriptomic profiles of MA tumors [4]. Some of them, like $A R$ itself or SPDEF, have putative androgene response elements (ARE). Moreover, AGR2 (androgeninducible gene anterior gradient-2) is highly induced by androgen in an androgen receptor (AR)-dependent manner. After all, the main trait of MA tumors is the activation of the AR pathway, and AR target genes could help to identify this tumor subgroup.

FOXA1 (Forkhead box protein A1), a member of the forkhead class of DNA-binding proteins, is a pioneer factor facilitating the recruitment of ER and AR to their response elements on the genome. In breast cancer, FOXA1 expression is highly correlated with $\mathrm{ER}(+), \mathrm{PR}(+)$ and endocrine signaling, and may have a prognostic value in ER(-) tumors [29]. Doane et al. reported that FOXA1 is overexpressed in the MA subtype [4]. In our study, according to the transcriptomic definition of our MA group (ER(-) AR(+) FOXA1(+)), up to $90 \%$ of MA tumors were also FOXA1 positive by IHC. However, $31 \%$ of BL tumors were positive as well, thus making FOXA1 immunostaining not specific enough to identify MA tumors.

GCDFP15, the product of the AR-target gene PIP (Prolactin Induced Protein) [30], has been initially described as an apocrine marker. It is present at high concentrations in breast cyst fluid [24] but also expressed in ER(+) or ER(-) breast carcinomas. To date, it is routinely used for the diagnosis of metastasis of unknown origin to identify tumors coming from the breast, with $95 \%$ specificity and $74 \%$ sensitivity [24,31]. GCDFP15 mRNA are also overexpressed in MA tumors [4]. However, in our study, GCDFP15 was not more sensitive than AR to identify MA tumors when analyzed alone by IHC (57\% IHC GCDFP15(+) in the MA group). Our results also showed that GCDFP15 negativity was constant in BL tumors. Therefore, in ER(-) tumors, GCDFP15 positive IHC staining seems to be highly specific of MA cancers but not very sensitive of this subtype.

We then analyzed the sensitivity and specificity of the potentially relevant following IHC signatures: AR alone, AR AND FOXA1, HER2 OR GCDFP15. Doane et al. [4] also proposed one IHC signature without AR: ER(-) PR(-) $\operatorname{ALCAM}(+)$ and $\operatorname{SPDEF}(+)$, but this signature was validated on only 10 MA tumors. Besides that, ALCAM/ SPDEF immunostainings are not widely used and have not been standardized so far. Niemeier et al. [28] reported that the tumors with the IHC profiles ER(-) HER2(3+) AR(+) or ER(-) HER2(-) AR(+) may be MA tumors but it is likely that other MA tumors will be missed with this definition centered on AR IHC. We propose here, in ER(-) breast tumors, a composite signature including AR gene expression pathway analysis by qRT-PCR in addition to "HER2(3 +) or GCDFP15(+)" protein expression by IHC. Our IHC signature is composed of validated immunostainings, with international guidelines, used on a daily basis in pathology laboratories. The qRT-PCR profile can be easily obtained on frozen tissue, provided that a frozen-tissue workflow is organized. The validation of quantification on formalinfixed paraffin-embedded tissues is under way and will allow qRT-PCR analysis on almost all samples.

We also analyzed other molecular alterations in these MA tumors. The phosphatidylinositol-3 kinase (PI3K) signaling pathway is crucial for cell growth and cell survival. Mutations in the gene encoding the p110a (PIK3CA) subunit of PI3K are commonly found in breast cancer. Gonzales-Angulo et al. [32] reported a possible association between the level of AR and PIK3CA mutations. In our study, although we found $P I K 3 C A$ mutations only in MA tumors, the difference was not statistically significant; however, the number of patients was low. Also, no difference in $A R$ mRNA expression level could either be detected in the PIK3CA mutated group of MA tumors compared to the PIK3CA wild type counterpart (data not shown).

TP53 mutations are commonly found in ER(-) breast cancer, and nearly $90 \%$ in the triple negative subgroup, but were present in only $50 \%$ of our MA tumors. In prostate cancer cells, it was described that loss of p53 function contributes to increased AR expression [33]. In our study, no differences in AR expression could be detected in the p53 nonfunctional subgroup of MA tumors compared to the functional p53 group (data not shown). This potential link between AR and p53 should be further evaluated. 
In breast cancers, AR is overexpressed in up to $70 \%$ of cases [34], mainly in luminal and low grade tumors $[6,35]$. This expression has been associated with a favorable outcome in ER(+) tumors [36,37] as well as in ER(-) tumors $[35,38,39]$

Little is known about the clinical outcome of MA carcinomas, as very few tumors were available in previous transcriptomic studies (six specimens in the works of Farmer et al. [3], and nine in Doane et al. [4]). In our study cohort, demographic or clinical presentation did not show specific features. We did not find any association with Cowden disease, as reported by some authors [40]. Though limited by small sample size and retrospective review, we found that MA tumor phenotypes appeared to be rather aggressive, with a high proportion of poor prognosis factors (grade SBR3, lymphovascular invasion, node involvement). They were also associated with a poor clinical outcome despite the fact that the wide majority of patients received chemotherapy.

Recently, Lehmann et al. [41] re-analyzed 21 breast data sets, including 587 triple negative breast carcinomas (TNBC), and identified a new TNBC subtype called "luminal androgen receptor" (LAR) type. Though not named "molecular apocrine" and all being HER2(-), these 62 LAR tumors seemed to be included in the MA group. Relapse free survival was significantly decreased in the LAR subtype compared with other TNBC subtypes.

\section{Conclusions}

Finally, our study demonstrates that we could accurately identify MA breast tumors by AR pathway analysis by qRT-PCR, in addition to HER2 or GCDFP15 protein overexpression by IHC. This composite tool may be sensitive, specific and useful to differentiate ER negative tumors in $\mathrm{MA}$ or $\mathrm{BL}$, in daily practice. Accurate identification of MA tumors could help to include these patients with rather aggressive tumors in specific "AR-pathway" therapeutic trials or to identify other therapeutic targets.

\section{Additional material}

Additional file 1: Molecular apocrine qRT-PCR signature in the 45 ER(-) tumors defined by the microarray predictor. The 45 tumors are defined to be molecular apocrine (MA) or basal-like (BL) by the microarray predictor. The mRNA expression of AR, FOXA1, AGR2, ALCAM, SPDEF, UGT2B28A and TTF3 is evaluated by q RT-PCR, expressed as relative ratio and compared between transcriptionaly defined $\mathrm{MA}$ and $\mathrm{BL}$ tumors.

Additional file 2: DFS curves of the 54 ER(-) MA tumors according to AR, HER2 and GCDFP15 immunostainings.

\section{Abbreviations}

AGR2: androgen-inducible gene anterior gradient-2; AR: androgen receptor; ARE: androgene response element; AUC: area under the receiver operating characteristics curve; BL: basal-like; DFS: disease free survival; ER: estrogen receptor alpha; FASAY: functional assay in yeast; HER2: Human Epidermal Growth Factor Receptor 2; IHC: immunohistochemistry; LAR: luminal androgen receptor; MA: molecular apocrine; MCA: multiple correspondence analysis; OS: overall survival; PI3K: phosphatidylinositol-3 kinase; q-RT PCR: quantitative reverse transcription PCR; TNBC: triple negative breast cancer

\section{Competing interests}

The authors declare that they have no competing interests.

\section{Authors' contributions}

$J L C, A S H$ and PB designed the study, collected and analyzed the data, and wrote the manuscript. JLC and ASH contributed equally to this work. RP carried out all the statistical analyses. MB carried out the biological data collection, the data management and contributed to data analysis. FB carried out all immunohistochemical stainings.

$\mathrm{HH}$ and SLD carried out the clinical data collection with review of the medical charts and survival follow-up. PB and AdR carried out all diagnoses and pathological interpretations. $L C D, E B, C d B$ and $M A$ obtained fresh frozen tissues sections under optimal conditions for all the biological studies. SG and CC enrolled patients. ME contributed to the design of the study, enrolled patients and contributed to data collection. PdC, AJ and $\mathrm{HdT}$ read and critically revised the manuscript. All authors read and approved the final manuscript.

\section{Acknowledgements}

We thank all the technicians of St. Louis Hospital Pathology Department and the technicians of the Biochemistry Department (Catherine Brunin, Claire Bocquet, Odile Flinois, Laurence Françoise, Brice Geslot, Martine Legrand and Evelyne Wittmer) for their contribution to pathological and molecular analysis. We especially thank Aurélien de Reynies for helpful discussions.

\section{Authors' details}

${ }^{1}$ AP-HP, Hosp Saint-Louis, Laboratory of Biochemistry, 1 av C. Vellefaux, Paris, 75010, France. ${ }^{2}$ CNRS UMR7212/INSERMU944, IUH, 1 av C. Vellefaux, Paris, 75010, France. ${ }^{3}$ University Paris Diderot, Sorbonne Paris Cité, Paris, 75010, France. ${ }^{4}$ AP-HP, Hosp Saint-Louis, Breast Diseases Center, 1 av C. Vellefaux, Paris, 75010, France. ${ }^{5}$ AP-HP, Hosp Saint-Louis, Biostatistic Department, 1 av C. Vellefaux, Paris 75010, France. ${ }^{6}$ AP-HP, Hosp Saint-Louis, Laboratory of Pathology, 1 av C. Vellefaux, Paris, 75010, France. ${ }^{7}$ INSERM UMR_S728, 1 av C. Vellefaux, Paris, 75010, France. ${ }^{8}$ AP-HP, Hosp Saint-Louis, Department of Surgery, 1 av C. Vellefaux, Paris, 75010, France. ${ }^{9}$ AP-HP, Hosp Saint-Louis, Department of Radiology, 1 av C. Vellefaux, Paris, 75010, France.

Received: 14 September 2012 Revised: 20 February 2013

Accepted: 11 May 2013 Published: 11 May 2013

\section{References}

1. Birrell SN, Hall RE, Tilley WD: Role of the androgen receptor in human breast cancer. J Mammary Gland Biol Neoplasia 1998, 3:95-103.

2. Park S, Koo J, Park HS, Kim J-H, Choi S-Y, Lee JH, Park B-W, Lee KS: Expression of androgen receptors in primary breast cancer. Ann Oncol 2010, 21:488-492.

3. Farmer $\mathrm{P}$, Bonnefoi $\mathrm{H}$, Becette $\mathrm{V}$, Tubiana-Hulin $\mathrm{M}$, Fumoleau $\mathrm{P}$, Larsimont D, Macgrogan G, Bergh J, Cameron D, Goldstein D, Duss S, Nicoulaz A-L, Brisken C, Fiche M, Delorenzi M, Iggo R: Identification of molecular apocrine breast tumours by microarray analysis. Oncogene 2005, 24:4660-4671.

4. Doane AS, Danso M, Lal P, Donaton M, Zhang L, Hudis C, Gerald WL: An estrogen receptor-negative breast cancer subset characterized by a hormonally regulated transcriptional program and response to androgen. Oncogene 2006, 25:3994-4008.

5. Guedj M, Marisa L, de Reynies A, Orsetti B, Schiappa R, Bibeau F, MacGrogan G, Lerebours F, Finetti P, Longy M, Bertheau P, Bertrand F, Bonnet F, Martin AL, Feugeas JP, Bièche I, Lehmann-Che J, Lidereau R, Birnbaum D, Bertucci F, de Thé $H$, Theillet $C$ : A refined molecular taxonomy of breast cancer. Oncogene 2012, 31:1196-1206.

6. Moinfar F, Okcu M, Tsybrovskyy O, Regitnig P, Lax SF, Weybora W, Ratschek M, Tavassoli FA, Denk H: Androgen receptors frequently are expressed in breast carcinomas: potential relevance to new therapeutic strategies. Cancer 2003, 98:703-711. 
7. Marisa L, de Reynies A, Guedj M: citbcmst: Assigning tumor samples to CIT Breast Cancer Molecular Subtypes from gene expression data. [http://cran.r-project.org/web/packages/citbcmst/index.html].

8. Latil A, Bièche I, Vidaud D, Lidereau R, Berthon P, Cussenot O, Vidaud M: Evaluation of androgen, estrogen (ERa and ER $\beta$ ), and progesterone receptor expression in human prostate cancer by real-time quantitative reverse transcription-polymerase chain reaction assays. Cancer Res 2001, 61:1919-1926.

9. Budczies J, Klauschen F, Sinn BV, Györffy B, Schmitt WD, Darb-Esfahani S, Denkert C: Cutoff Finder: a comprehensive and straightforward Web application enabling rapid biomarker cutoff optimization. PLOS ONE 2012, 7:e51862.

10. Lehmann-Che J, Amira-Bouhidel F, Turpin E, Antoine M, Soliman H, Legres L, Bocquet C, Bernoud R, Flandre E, Varna M, de Roquancourt A, Plassa L-F, Giacchetti S, Espié M, de Bazelaire C, Cahen-Doidy L, Bourstyn E, Janin A, de Thé H, Bertheau P: Immunohistochemical and molecular analyses of HER2 status in breast cancers are highly concordant and complementary approaches. Br J Cancer 2011, 104:1739-1746.

11. Flaman JM, Frebourg T, Moreau V, Charbonnier F, Martin C, Chappuis $P$, Sappino AP, Limacher IM, Bron L, Benhattar J: A simple p53 functional assay for screening cell lines, blood, and tumors. Proc Natl Acad Sci USA 1995, 92:3963-3967.

12. Waridel F, Estreicher A, Bron L, Flaman JM, Fontolliet C, Monnier P, Frebourg T, Iggo R: Field cancerisation and polyclonal p53 mutation in the upper aero-digestive tract. Oncogene 1997, 14:163-169.

13. Varna M, Lehmann-Che J, Turpin E, Marangoni E, El Bouchtaoui M, Jeanne M, Grigoriu C, Ratajczak P, Leboeuf C, Plassa L-F, Ferreira I, Poupon M-F, Janin A, de Thé H, Bertheau P: p53 dependent cell cycle arrest triggered by chemotherapy in xenografted breast tumors. Int $J$ Cancer 2009, 124:991-997.

14. Santarpia M, Altavilla G, Margeli M, Cirauqui B, Mesiti M, Cavallari V, Ramirez JL, Sanchez-Ronco M, Santarpia L, Taron M, Rosell R: PIK3CA mutations and BRCA1 expression in breast cancer: potential biomarkers for chemoresistance. Cancer Invest 2008, 26:1044-1051.

15. Wolff AC, Hammond ME, Schwartz JN, Hagerty KL, Allred DC, Cote RJ, Dowsett M, Fitzgibbons PL, Hanna WM, Langer A, McShane LM, Paik S, Pegram MD, Perez EA, Press MF, Rhodes A, Sturgeon C, Taube SE, Tubbs R, Vance GH, van de Vijver M, Wheeler TM, Hayes DF, American Society of Clinical Oncology/College of American Pathologists: American Society of Clinical Oncology/College of American Pathologists guideline recommendations for human epidermal growth factor receptor 2 testing in breast cancer. Arch Pathol Lab Med 2007, 131:18-43.

16. Gown AM: Current issues in ER and HER2 testing by IHC in breast cancer. Mod Pathol 2008, 21(Suppl 2):S8-S15.

17. Breiman L, Friedman JH, Olshen RA, Stone CJ: Classification and Regression Trees London: Chapman and Hall; 1984.

18. Shih Y-S: Selecting the best splits for classification trees with categorical variables. Stat Probabil Lett 2001, 54:341-345.

19. R Development Core Team: R: A Lanquage and Environment for Statistical Computing Vienna, Austria: R Foundation for Statistical Computing; 2009.

20. Ripley B: Tree: Classifcation and Regression Trees 2010. R package version 1.028 [http://CRAN.R-project.org/package=tree].

21. O'Malley FP, Page DL, Nelson EH, Dupont WD: Ductal carcinoma in situ of the breast with apocrine cytology: definition of a borderline category. Hum Pathol 1994, 25:164-168.

22. Tavassoli FA, Norris HJ: Intraductal apocrine carcinoma: a clinicopathologic study of 37 cases. Mod Pathol 1994, 7:813-818.

23. Tavassoli FA, Devilee P, World Health Organization: Tumours of the Breast and Female Genital Organs - Pathology and Genetics Lyon, France: IARC Press; 2003.

24. Zagorianakou P, Zagorianakou N, Stefanou D, Makrydimas G, Agnantis NJ: The enigmatic nature of apocrine breast lesions. Virchows Arch 2006, 448:525-531.

25. Weigelt $B$, Horlings HM, Kreike B, Hayes MM, Hauptmann M, Wessels LF, de Jong D, Van de Vijver MJ, Van't Veer $L$, Peterse JL: Refinement of breast cancer classification by molecular characterization of histological special types. J Pathol 2008, 216:141-150.

26. Celis JE, Cabezón T, Moreira JM, Gromov P, Gromova I, TimmermansWielenga V, Iwase T, Akiyama F, Honma N, Rank F: Molecular characterization of apocrine carcinoma of the breast: validation of an apocrine protein signature in a well-defined cohort. Mol Oncol 2009, 3:220-237.

27. Vranic S, Gatalica Z, Deng H, Frkovic-Grazio S, Lee LM, Gurjeva O, Wang ZY: ER-a36, a novel isoform of ER-a66, is commonly over-expressed in apocrine and adenoid cystic carcinomas of the breast. J Clin Pathol 2011, 64:54-57.

28. Niemeier LA, Dabbs DJ, Beriwal S, Striebel JM, Bhargava R: Androgen receptor in breast cancer: expression in estrogen receptor-positive tumors and in estrogen receptor-negative tumors with apocrine differentiation. Mod Pathol 2010, 23:205-212.

29. Albergaria A, Paredes J, Sousa B, Milanezi F, Carneiro V, Bastos J, Costa S, Vieira D, Lopes N, Lam EW, Lunet N, Schmitt F: Expression of FOXA1 and GATA-3 in breast cancer: the prognostic significance in hormone receptor-negative tumours. Breast Cancer Res 2009, 11:R40.

30. Baniwal SK, Little GH, Chimge N-O, Frenkel B: Runx2 controls a feedforward loop between androgen and prolactin-induced protein (PIP) in stimulating T47D cell proliferation. J Cell Physiol 2012, 227:2276-2282.

31. Wick MR, Lillemoe TJ, Copland GT, Swanson PE, Manivel JC, Kiang DT: Gross cystic disease fluid protein-15 as a marker for breast cancer: immunohistochemical analysis of 690 human neoplasms and comparison with alpha-lactalbumin. Hum Pathol 1989, 20:281-287.

32. Gonzalez-Angulo AM, Stemke-Hale K, Palla SL, Carey M, Agarwal R, MericBerstam F, Traina TA, Hudis C, Hortobagyi GN, Gerald WL, Mills GB, Hennessy BT: Androgen receptor levels and association with PIK3CA mutations and prognosis in breast cancer. Clin Cancer Res 2009, 15:2472-2478.

33. Alimirah F, Panchanathan R, Chen J, Zhang X, Ho SM, Choubey D: Expression of androgen receptor is negatively regulated by $\mathrm{p} 53$. Neoplasia 2007, 9:1152-1159.

34. Collins LC, Cole KS, Marotti JD, Hu R, Schnitt SJ, Tamimi RM: Androgen receptor expression in breast cancer in relation to molecular phenotype: results from the Nurses' Health Study. Mod Pathol 2011, 24:924-931.

35. Loibl S, Müller BM, von Minckwitz G, Schwabe M, Roller M, Darb-Esfahani S, Ataseven B, du Bois A, Fissler-Eckhoff A, Gerber B, Kulmer U, Alles JU, Mehta $\mathrm{K}$, Denkert $C$ : Androgen receptor expression in primary breast cancer and its predictive and prognostic value in patients treated with neoadjuvant chemotherapy. Breast Cancer Res Treat 2011, 130:477-487.

36. Gonzalez LO, Corte MD, Vazquez J, Junquera S, Sanchez R, Alvarez AC, Rodriguez JC, Lamelas ML, Vizoso FJ: Androgen receptor expression in breast cancer: relationship with clinicopathological characteristics of the tumors, prognosis, and expression of metalloproteases and their inhibitors. BMC Cancer 2008, 8:149.

37. Hu R, Dawood S, Holmes MD, Collins LC, Schnitt SJ, Cole K, Marotti JD, Hankinson SE, Colditz GA, Tamimi RM: Androgen receptor expression and breast cancer survival in postmenopausal women. Clin Cancer Res 2011, 17:1867-1874.

38. Agoff SN, Swanson PE, Linden H, Hawes SE, Lawton TJ: Androgen receptor expression in estrogen receptor-negative breast cancer. Immunohistochemical, clinical, and prognostic associations. Am J Clin Pathol 2003, 120:725-731.

39. Luo X, Shi Y-X, Li Z-M, Jiang W-Q: Expression and clinical significance of androgen receptor in triple negative breast cancer. Chin J Cancer 2010, 29:585-590.

40. Banneau G, Guedj M, MacGrogan G, de Mascarel I, Velasco V, Schiappa R, Bonadona V, David A, Dugast C, Gilbert-Dussardier B, Ingster O, Vabres P, Caux F, de Reynies A, Iggo R, Sevenet N, Bonnet F, Longy M: Molecular apocrine differentiation is a common feature of breast cancer in patients with germline PTEN mutations. Breast Cancer Res 2010, 12:R63.

41. Lehmann BD, Bauer JA, Chen X, Sanders ME, Chakravarthy AB, Shyr Y, Pietenpol JA: Identification of human triple-negative breast cancer subtypes and preclinical models for selection of targeted therapies. Clin Invest 2011, 121:2750-2767.

\section{doi:10.1186/bcr3421}

Cite this article as: Lehmann-Che et al: Molecular apocrine breast cancers are aggressive estrogen receptor negative tumors overexpressing either HER2 or GCDFP15. Breast Cancer Research 2013 15: R37. 